\title{
LA-UR-15-21263
}

Approved for public release; distribution is unlimited.

Title: Mechanical Properties of AM Stainless Steel Parts and Repair Welds

Author(s): $\quad$ Vogel, Sven C.

Carpenter, John S.

Intended for: Report

Issued:

2015-02-22 
Disclaimer:

Los Alamos National Laboratory, an affirmative action/equal opportunity employer,is operated by the Los Alamos National Security, LLC for the National NuclearSecurity Administration of the U.S. Department of Energy under contract DE-AC52-06NA25396. By approving this article, the publisher recognizes that the U.S. Government retains nonexclusive, royalty-free license to publish or reproduce the published form of this contribution, or to allow others to do so, for U.S. Government purposes. Los Alamos National Laboratory requests that the publisher identify this article as work performed under the auspices of the U.S. Departmentof Energy. Los Alamos National Laboratory strongly supports academic freedom and a researcher's right to publish; as an institution, however, the Laboratory does not endorse the viewpoint of a publication or guarantee its technical correctness. 


\section{Mechanical Properties of AM Stainless Steel Parts and Repair Welds}

PI: John Carpenter (MST-6)

Funding Agency: C1 (\$14K)

Goals:

- Advance certification of AM materials

- Compare microstructure and its evolution during processing and deformation between AM fabricated and conventional steels

Deliverables Achieved:

- Measured texture data for 17 steel samples on HIPPO, including material planned to be shocked in pRAD in FY16

- Quantified texture and austenite/ferrite phase fractions

- Provide input data for deformation modeling

As wrought

$\gamma$ only

AM, as fabricated $\alpha \sim 4$ wt. \%

$\gamma \sim 96$ wt. $\%$
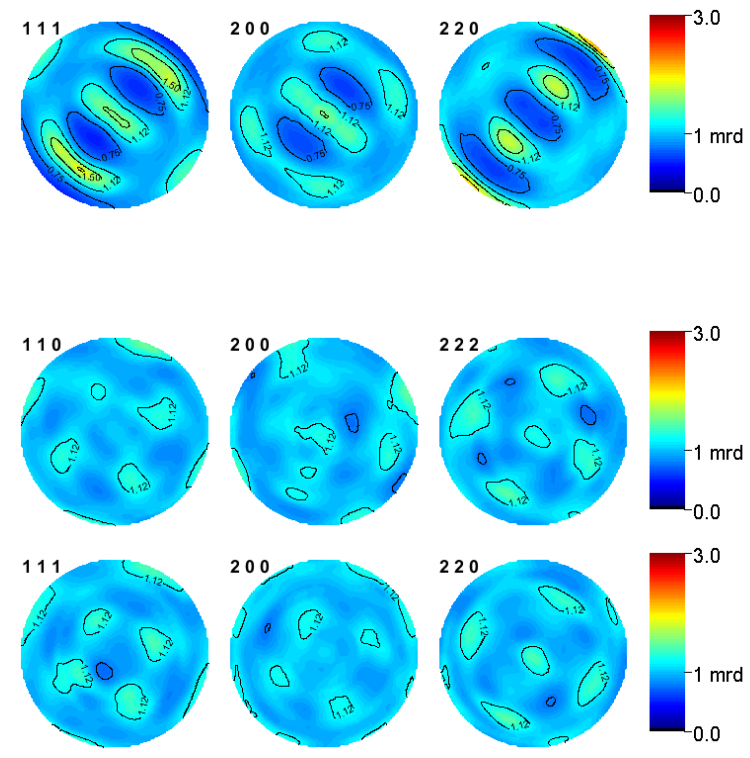

Texture of as wrought (top) and AM produced 316L steel (bottom). The conventional materials was purely austenite, while the AM material showed $\sim 4$ wt.\% ferrite (upper pole figures).

Proposed Work for Fy'16: (optional)

- In situ annealing studies

- Study influence of synthesis parameters on microstructure (texture, composition)

- Perform imaging/tomography on AM samples 